\title{
Analysis of the Thematic Progression of English Prose Youth
}

\author{
Wang Qingwei and Feng Zongxiang
}

\begin{abstract}
This article takes the famous English prose poem of Youth written by Samuel Ullman as an example to analyze the relationship between thematic progression and characteristic of the passage. Results of the study showed that the article is logically coherent and well-connected under the influence of the staircase pattern. The radioactive pattern, convergent pattern and parallel pattern form the prominent subject and swift narration. Together with the parallel pattern, the comparison between clauses makes the demonstration sharp and powerful. At the same time, the article also discussed the subtle relationship between the genre and thematic progression, that is, different genres have different preferences for the thematic progression. Great ideas need to be expressed in appropriate genres, and specific genre calls for the corresponding thematic progression.
\end{abstract}

Index Terms-Youth, thematic progression, genre, thematic analysis

\section{INTRODUCTION}

The author of Youth, Samuel Ullman is not a poet with many works. He only wrote this prose poem in his life, and he wrote it to encourage himself when he was seventy years old. He lived in poverty, but he did not give up on himself, instead, he was aggressive and continued to struggle for his ideals. $\mathrm{He}$ finally created his own career and spent his life full of happiness and youth. The work of Youth has been loved by many people. They have used it as their own life motto and put them into the soul to inspire themselves to realize the value of life.

Articles carry the profound and eternal philosophy with the words and the clauses, inspiring endless people. Why do great works have these qualities? We may start by analyzing its form, because the form not only carries the content, but also contains the logic and language style. The thematic progression is a widely-used language analysis method and an important form of text generation. [1], [2] was the first to reveal that there would be a certain connection between theme and the discourse genre. Since then, many scholars have started conducting studies on the relationship between thematic progression patterns and discourse genres and have made a great number of achievements. However, discourses analyzed are mostly novels, advertisements, technical discourses and political speeches [3], few studies pay attention to prose poem from the perspective of thematic progression patterns. From the perspective of thematic progression, this article takes the famous English prose poem

Manuscript received August 27, 2019; revised September 12, 2019.

Wang Qingwei is with Northwestern Polytechnical University, Xi'an, China (e-mail: xiaowa@mail.nwpu.edu.cn). of Youth as an example to analyze the secret of great works, that is, how to achieve the rigorous logic, prominent themes, powerful statements and the unity of form and content.

\section{Thematic Structure AND Thematic Progression}

\section{A. Thematic Structure}

The concept of the theme structure was first proposed by the founder of the Prague School, Matthew Hughes. He believes that a sentence can be divided into three parts: Theme, Rheme and Transition. Theme is the starting point of the discourse, and rheme is the words around the subject, usually the core content of the discourse. Transition is the transitional component that connects the theme and rheme [4]. Afterwards, many linguists continued to explore this issue. Among them, Halliday further developed the theory of thematic structure in the framework of systemic functional grammar. According to Halliday, the subject is the starting point of the clause information and the component of the clause. The rheme is a statement of the subject and contents carried out around the theme [5].

\section{B. Simple Theme and Multiple Theme}

\section{1) Simple theme}

Single themes refer to themes that contain only experiential components but no interpersonal or textual component. It may consist of noun phrases, adverb phrases, prepositional phrases, or clauses.

E.g.1

(1) The frog in the pond (T) // is croaking (R).

(2) Quickly (T) // the boy ran to his mother (R).

(3) For the sake of people (T) // they fought the enemy bravely $(\mathrm{R})$.

(4) Tom and Jim (T) // are playing computer games (R).

2) Multiple theme

TABLE I: EXAMPLE OF MULTIPLE THEME

\begin{tabular}{|c|c|c|c|c|c|c|c|}
\hline Well & but & then & Ann & surely & wouldn't & $\begin{array}{c}\text { the best } \\
\text { idea }\end{array}$ & $\begin{array}{l}\text { be to } \\
\text { join the } \\
\text { group. }\end{array}$ \\
\hline continuative & structural & conjunctive & vocative & modal & finite & topical & \multirow[b]{2}{*}{ rheme } \\
\hline \multicolumn{3}{|c|}{ textual } & \multicolumn{3}{|c|}{ interpersonal } & experiential & \\
\hline
\end{tabular}

Multiple theme refers to themes that contain multiple semantic components, which must have an experiential component, and one or both of the interpersonal component and textual component. The following table (Table I) shows an example of multiple theme. When the three components exist at the same time, their order is generally the textual components, interpersonal components, and experiential 
components. The experiential component can also be called the topic theme.

\section{3) Thematic progression}

From the above introduction, Matthew and Halliday's discussions focus more on the theme-rheme segmentation within clauses. However, when we enter the discourse level, we will find the limitations of this analysis method. To understand the discourse, we should not only understand the thematic relationship within individual clauses, but also understand how the content and meaning of the whole text unfold and how the information flows. [6] first proposed the concept of thematic progression, that is, "When a set of meaningful sentences constitute a coherent discourse, some kind of connection and change will occur among the themes and rhemes of the clauses, promoting the orderly development of discourse. The connection and change is called the thematic progression [5]. From the perspective of the thematic progression, we can find that although the genres are diverse and the language styles are different, the discourses can all be regarded as an advancing sequence of theme. With the progression of themes in the sequence, meaning gradually unfolds, and the logical relationship between clauses is established layer by layer, which eventually forms a whole with close internal connection and smooth external expression.

Thematic progression in different genres has its own characteristics. Some specific text can be a complex of different thematic progression patterns. Numerous scholars at home and abroad have studied the characteristics and laws of thematic progression, and summed up many thematic progression patterns. In addition to the five thematic progression patterns proposed by Danes, there are four thematic progression patterns proposed by [7], seven thematic progression patterns proposed by [8], six thematic progression patterns summarized by [9], three thematic progression patterns proposed by [10] and four thematic progression patterns proposed by [11]. After doing a comparative research, we summarized five thematic progression patterns:

\section{(1) Radioactive pattern}

For radioactive pattern, shown as Fig. 1, several clauses have the same theme or are part of the same theme and have different rhemes.

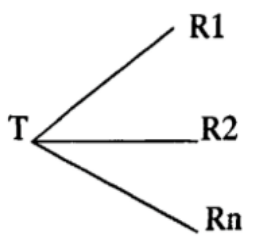

Fig. 1. Radioactive pattern.

E.g. 2 Beijing is a large city. It's the nation's political center. It's home to the headquarters of many Chinese large companies.

(2) Convergent pattern

As Fig. 2 presents, in convergent pattern, several clauses share the same rheme but have different themes.

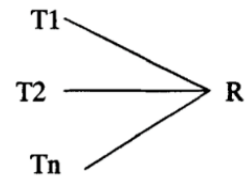

Fig. 2. Convergent pattern.

E.g. 3 Tom likes to play basketball, Jenny likes to play basketball, everyone likes to play basketball.

(3) Staircase pattern

Fig. 3 shows the staircase pattern, the theme of the latter clause is the rheme of the former clause.

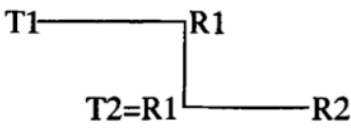

Fig. 3. Staircase pattern.

E.g. 4 Kate bought a cellphone. It was made in China. China is a developing country.

(4) Overlapping pattern

For the overlapping pattern, as Fig. 4 displays, the theme and rheme of the latter clause intersect with the theme and rheme of the former clause partially or totally.

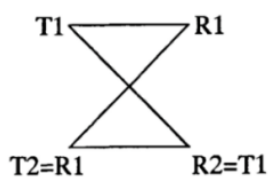

Fig. 4. Overlapping pattern.

E.g. 5 Danny bought a car. It was very cool. Danny liked cool things.

(5) Parallel pattern

Fig. 5 provides the parallel pattern, in which the rheme changes with the alternation of two themes.

$\begin{array}{ll}\text { T1-R1 } & \text { T2-R2 } \\ \text { T3-R3 } & \text { T4-R4 } \\ \text { T(n-1)-R(n-1) } & \text { Tn-Rn }\end{array}$

Fig. 5. Parallel pattern.

E.g. 6 Dogs are active in the daytime; Cats are spiritual in the evening. Dogs can't stretch their paws; Cats can. Dogs like to be in groups; Cats like to be alone.

In order to arrange information reasonably and avoid the monotony of form, no text will use the same pattern from beginning to end, but a mixture of different patterns [4].

\section{RESEARCH QUESTIONS}

Against this background, we formed the following research questions with regard to our target text, English prose poem of Youth:

RQ1: How is the text in Youth unified in form and content by using different thematic progression patterns?

RQ2: What is the relationship between thematic progression and genre?

\section{ANALYSIS}

According to the structure of the article, the text of Youth 
is divided into three parts for analysis.

Part I

Youth is not a time of life; it is a state of mind; it is not a matter of rosy cheeks, red lips and supple knees; it is a matter of the will, a quality of the imagination, a vigor of the emotions; it is the freshness of the deep springs of life.

Part II

Youth means a temperamental predominance of courage over timidity, of the appetite for adventure over the love of ease. This often exists in a man of sixty more than a boy of twenty. Nobody grows old merely by a number of years. We grow old by deserting our ideals.

Years may wrinkle the skin, but to give up enthusiasm wrinkles the soul. Worry, fear, self-distrust bows the heart and turns the spirit back to dust.

\section{Part III}

Whether sixty or sixteen, there is in every human being's heart the lure of wonder, the unfailing child-like appetite of what's next, and the joy of the game of living. In the center of your heart and my heart there is a wireless station; so long as it receives messages of beauty, hope, cheer, courage and power from men and from the infinite, so long are you young.

When the aerials are down, and your spirit is covered with snows of cynicism and the ice of pessimism, then you are grown old, even at twenty, but as long as your aerials are up, to catch the waves of optimism, there is hope you may die young at eighty.

After dividing the text, the detail discourse analysis and thematic progression in each part is demonstrated. The analysis of part I is first illustrated through the following Table II and Fig. 6.

TABLE II: THEME AND RHEME IN PART I

\begin{tabular}{lcl}
\hline No. & Theme & Rheme \\
\hline 1 & Youth & is not a time of life; \\
\hline 2 & it & is a state of mind; \\
\hline 3 & it & is not a matter of rosy cheeks, red lips and supple knees; \\
\hline 4 & it & is a matter of the will, a quality of the imagination, a vigor of the emotions; \\
\hline 5 & it & is the freshness of the deep springs of life. \\
\hline
\end{tabular}

【1】 $\mathrm{T} 1$ - R1

【2】 $\mathrm{T} 2$ (=T1) - R2 (Contrary to R1)

【3】 $\mathrm{T} 3(=\mathrm{T} 1)-\mathrm{R} 3$

【4】 $\mathrm{T} 4$ (=T1) - R4 (Contrary to R3)

【5】 $\mathrm{T} 5$ (=T1) - $\mathrm{R} 5$

Fig. 6. Thematic progression in Part I.

From the analysis, it can be clearly seen that T1-T5 is exactly the same, and R1-R5 is different, which is a typical radioactive pattern. As the first part of the full text, the discourse was constructed around the theme at the beginning of paragraph, and five rhemes are used to discuss from different angles, which is very appealing. It is worth pointing out that the author maintains a good connection between different rhemes, that is, R1 and R2 are compared, R3 and R4 are compared, R5 is the summary and deepening of the rheme. The author's arrangement leaves readers a deep impression of the theme youth at first, and deepens their understanding through positive and negative comparison, summary and refinement. In the end, it's easy to draw the conclusion that youth is not external but internal.

From the analysis of this paragraph, we can find that radioactive thematic progression is very effective at the beginning of the article and can give readers a clear and definite impression quickly. The more unified themes are, the more prominent the topic is. Rational use of contrastive and deepening methods in rheme can further highlight the theme.

Then, the discourse analysis of part II shown as Table III and Fig. 7 are followed.

TABLE III: THEME AND RHEME IN PART II

\begin{tabular}{|c|c|c|}
\hline No. & Theme & Rheme \\
\hline 1 & Youth & $\begin{array}{l}\text { means a temperamental predominance of courage over } \\
\text { timidity, of the appetite for adventure over the love of ease. }\end{array}$ \\
\hline 2 & This & often exists in a man of sixty more than a boy of twenty. \\
\hline 3 & Nobody & grows old merely by a number of years. \\
\hline 4 & We & grow old by deserting our ideals. \\
\hline 5 & Years & may wrinkle the skin \\
\hline 6 & but to give up enthusiasm & wrinkles the soul. \\
\hline 7 & Worry, fear, self-distrust & bows the heart and turns the spirit back to dust. \\
\hline \multicolumn{3}{|c|}{ 【1】 $\mathrm{T} 1$ - R1 } \\
\hline & 【2】 & $\mathrm{T} 2(=\mathrm{R} 1)-\mathrm{R} 2\left(\mathrm{R}^{\prime}\right)$ \\
\hline & 【3】 & $\mathrm{T} 3$ - R3 (R') \\
\hline & 【4】 & T4 - R4 (R') \\
\hline & 【5】 & T5 (R3) - R5 \\
\hline & 【6】 & T6 (R4) - R6 \\
\hline
\end{tabular}

Fig. 7. Thematic progression in Part II.

This paragraph is the result of the joint action of the staircase pattern and convergent pattern. From 【1】 to【2】, it is a staircase pattern. The transformation from T1-R1 to R1-R2 successfully connects $\mathrm{T} 1$ to $\mathrm{R} 2$. The theme has changed from youth and inner to youth and years. R2-R4 goes deeper and deeper around the same rheme $\mathrm{R}^{\prime}$, that is, the relationship between aging and years. Therefore, 【2】 to【4】 are convergent patterns. Focused on expressing the author's view that youth and senility have nothing to do with years but with ideals and passions. Both of the patterns jointly express the view that youth and aging have nothing to do with years but with ideals and passions.

It is worth noting that between【3】【5】 and 【4】【6】, there could have been a staircase pattern, that is:

This often exists in a man of sixty more than a boy of twenty, no body grows old merely by a number of years, years (just) wrinkle the skin. We grow old by deserting out ideals, to give up enthusiasm wrinkles the soul.

It seems that the expression is a little smoother, but obviously not as good as the original. We can know the reason by comparing thematic progression in two forms.

Displayed as Figure 8, after the modification, the convergent pattern is not obvious, and the rheme $\mathrm{R}^{\prime}$ has become very vague. The author's thoughts about youth and age have been diluted. In addition, although there are two pairs of staircase pattern R3-T5 and R4-T6, which enhance 
the inheritance, the result is that the contrast between 【3】

【4】 and 【5】【6】 has also disappeared. It may be more important for narrative genres to express the succession of causes and consequences. However, the convergent pattern and the strong contrast of themes and rhemes between clauses are obviously more suitable for the prose genre of expressing the author's thoughts and feelings freely. Thus, the arrangement of the author is very precise from the perspective of thematic progression. All in all, this part further deepens the view that youth has nothing to do with years but with ideals and passions.

\begin{tabular}{|c|c|c|c|}
\hline \multirow{2}{*}{$\begin{array}{l}\text { Original: } \\
\text { 【1】 T1 - R1 }\end{array}$} & \multicolumn{3}{|c|}{ Modified: } \\
\hline & & 【1】 T1 - R1 & \\
\hline 【2】 & $\mathrm{T} 2$ (=R1) - R2 (R') & 【2】 & T2 (=R1) - R2 (R') \\
\hline 【3】 & T3 - R3 (R') & 【3】 & T3 - R3 (R') \\
\hline 【4】 & T4 - R4 (R') & 【5】 & T5 (R3) - R5 \\
\hline 【5】 & T5 (R3) - R5 & 【4】 & T4 - R4 (R') \\
\hline 【6】 & T6 (R4) - R6 & 【6】 & T6 (R4) - R6 \\
\hline 【7】 $\mathrm{T} 7$ - R7 & & 【7】 T7 - R7 & \\
\hline
\end{tabular}

Fig. 8. Two forms of thematic progression in Part II.

From the analysis of this part, we can find that different genres have different preferences for thematic progression. When we write articles, we need to choose the appropriate genre and use thematic progression pattern that matches the style of the selected genre. Besides, the staircase pattern often plays a role of succession. Theme-related rhemes that need to be emphasized can be discussed from multiple perspectives using the convergent pattern.

TABLE V: THEME AND RHEME IN PART III

\begin{tabular}{lcl}
\hline No. & Theme & \multicolumn{1}{c}{ Rheme } \\
\hline 1 & $\begin{array}{c}\text { Whether sixty or sixteen, } \\
\text { there }\end{array}$ & $\begin{array}{l}\text { is in every human being's heart the lure of wonder, the } \\
\text { unfailing child-like appetite of what's next, and the joy of } \\
\text { the game of living. }\end{array}$ \\
\hline 2 & $\begin{array}{c}\text { In the center of your heart } \\
\text { and my heart there }\end{array}$ & is a wireless station \\
\hline 3 & solong as it & $\begin{array}{l}\text { receives messages of beauty, hope, cheer, courage and } \\
\text { power from men and from the infinite }\end{array}$ \\
\hline 4 & solong are you & young \\
\hline 5 & When the aerials & are down \\
\hline 6 & and your spirit & is covered with snows of cynicism and the ice of pessimism, \\
\hline 7 & then you & are grown old, even at twenty, \\
\hline 8 & but as long as your aerials & are up, to catch the waves of optimism, \\
\hline 9 & there & is hope you may die young at eighty. \\
\hline
\end{tabular}

As tabulated in Table $\mathrm{V}$ and displayed in Fig. 9, from 【1】 to【3】, it's the staircase pattern. The transformation of $\mathrm{T} 1-\mathrm{R} 1=\mathrm{T} 2-\mathrm{R} 2=\mathrm{T} 3-\mathrm{R} 3$ naturally transforms the theme from the years described in the previous paragraph to the radio station receiving the signals of youth. From 【3】 to

【9】, there's three sets of parallel pattern, the two themes of people and radio alternately appeared, and the rheme changed accordingly. As to【8】 and 【9】Although limited by the lack of personal linguistic knowledge, it is hard to divide or explain the structure of 'there be' reasonably, it can still be concluded that the relationship between radio and human is discussed in 【8】【9】, that is, if the radio is always open, we will still be young when we pass away even at age 80. Therefore, it is acceptable to say that 【3】 to 【9】 are parallel patterns. By using the parallel pattern, this part illustrates the corresponding relationship between the radio receiving the youth signal and keeping young, suggesting that if people want to keep young, they should contact more people and things with young characteristics, instead of closing themselves and gradually withering away.

$\begin{array}{lc}\text { 【1】 } \mathrm{T} 1-\mathrm{R} 1 \\ \text { 【2】 } & \mathrm{T} 2-\mathrm{R} 2 \\ \text { 【3】 } & \mathrm{T} 3(=\mathrm{R} 2)-\mathrm{R} 3 \\ \text { 【4】 } & \mathrm{T} 4-\mathrm{R} 4 \\ \text { 【5】 } & \mathrm{T} 5(=\mathrm{R} 2)-\mathrm{R} 5 \\ \text { 【6】 } & \mathrm{T} 6(=\mathrm{T} 4)-\mathrm{R} 6 \\ \text { 【7】 } & \mathrm{T} 7 \text { (=T4) - R7 } \\ \text { 【8】 } & \mathrm{T} 8(=\mathrm{R} 2)-\mathrm{R} 8 \\ \text { 【9】 } & \mathrm{T} 9-\mathrm{R} 9\end{array}$

Fig. 9. Thematic progression in Part III.

The alternation of the two themes in the parallel pattern deepens the understanding of their relationship.

\section{DISCUSSION}

\section{A. Overlapping Pattern}

In this part, the writer will discuss why it is difficult to find traces of overlapping pattern in the full text. By analyzing the following example (E.g. 7) of overlapping pattern, the thematic progression presented in Figure 10, can be obtained.

E.g. 7

Mary (T1) bought a carpet (R1).

It (T2) was very expensive (R2).

Mary (T3) liked expensive things (R3).

$$
\begin{aligned}
& \text { 【1】 } \mathrm{T} 1-\mathrm{R} 1 \mid \\
& \text { 【2】 } \mathrm{T} 2(=\mathrm{R} 1)-\mathrm{R} 2 \\
& \text { 【3】 } \mathrm{T} 3(=\mathrm{T} 1)-\mathrm{R} 3(=\mathrm{R} 2)
\end{aligned}
$$

Fig. 10. Thematic progression in E.g. 7.

It can be seen that in overlapping pattern, connection between $\mathrm{T} 1$ and R2 is established in the end. However, in the situation of prose poem, the author needn't establishing such connections throughout the text. The clear Theme-Rheme relationship, strong expressive effect and smooth thematic progression are the author's requirements. Therefore, the author adopted a large number of radioactive patterns, convergent patterns and parallel patterns. The overlapping pattern, which emphasizes on logical reasoning, is applicable to argumentative or reasoning fiction genres that see the essence through the phenomena. Thus, it is reasonable that the overlapping pattern does not appear. This again illustrates the view that writing needs to choose a suitable genre and a thematic progression pattern that is appropriate to the genre used. 


\section{B. Relationship between Genres and Thematic Progression Patterns}

Like language, discourse genre is also a social symbol system. Purposes of different discourse genres can be achieved by means of the language level. [1] proposed the following hypothesis: the thematic progression mode corresponds to the discourse genre. He believes that narrative discourses are dominated by radioactive patterns, while staircase patterns are mainly applied in declarative discourses Many linguists have conducted deep studies on the relationship between the thematic progression patterns and genres, and have come to a convincing conclusion.

[12] Analyzed thematic progression in texts of stipulated style and those of narrative style, and discussed the relationship between thematic progression, stylistic type and the theme. After the analysis, they indicated that texts of different genres tend to have different features in thematic structures. In texts of stipulated style, parallel pattern holds dominant position, and radioactive pattern is not often used. But in texts like news and novels, parallel pattern is used with unremarkable frequency. The differences in the use the thematic progression patterns are closely related to the features of discourse genres. Concise and solemn expression are linguistic features of texts of stipulated style, thus, parallel pattern is mostly used. Narrative texts have to show fleshy plots or vivid artistic features, thus they are often written in an episodic format and connected by different patterns.

A large number of discourse analyses indicate that although there are texts applying a single basic thematic progression pattern, combination of several patterns is more used in texts [11]. The prose poem Youth is no exception. According to the analysis, Ullman did not apply only one simple thematic progression pattern, instead, different patterns were selected in different parts of the article, and the best expression effect was achieved through the combination of various thematic progression patterns. Specifically, staircase pattern is used for three times, while radioactive pattern, convergent pattern and parallel pattern appear only once. Similar to this result, [13] found out that staircase pattern is mostly used thematic progression pattern in the Chinese prose My Private Library and that in English version. Then comes radiation type, overlapping pattern and other patterns. But [14] analyzed the discourse structure of the prose Of Studies written by Francis Bacon and presented that the article witnesses the relatively frequent use of radioactive pattern and staircase pattern, besides, convergent patterns are also applied. The analysis of [15], who discussed the thematic progression in Russell's What I Have Lived for also indicates the wide application of connection of radioactive pattern and convergent pattern in the prose genre.

\section{CONCLUSION}

This paper analyses the full text of Youth from the perspective of thematic structure and thematic progression. From the perspective of article structure, the first part outlines what youth is. The second part focuses on the core meaning of youth, that is, youth has nothing to do with years but with ideals and passions. The third part discusses how to maintain youth. From the perspective of thematic progression mode, the characteristics of logical coherence and orderly cohesion are attributed to the staircase pattern adopted in the process of thematic progression. The bright and prominent features of the thesis are resulted from the adoption of radioactive pattern, convergent pattern and parallel pattern. The powerful discourse is the result of the parallel pattern and the contrast between themes and rhemes in each clause. Through the comprehensive use of various modes, the full text is free and logical.

At the same time, this paper explores the relationship between genre and thematic progression, and draws the conclusion that different genres have different preferences for thematic progression. Composition requires to choose the appropriate genre and use thematic progression mode that matches the selected genre style.

\section{ACKNOWLEDGMENT}

A. Wang Qingwei firstly thanks Associate Professor Feng Zongxiang, her supervisor, who has offered her valuable suggestions in the academic studies. He has spent much time reading and provided me with inspiring advice while preparing and revising this article.

Also, many thanks to Professor Zhang Yi, who has taught me the scientific research methodology in applied linguistics and Professor Zhao Xueai, who took me into the world of systematic functional linguistics. All of their intellectual ingenuity help me a lot in writing this article and will be of great significance to my future study.

Finally, the conference specialist Ms. Kate Hou is to be thanked for her warm help during the submission and registration.

\section{REFERENCES}

[1] P. H. Fries, "On the status of theme in English: Arguments from discourse," in Micro and Macro Connexity of Texts, J. S. Petofi and E. Sozer, Eds. Hamburg: Buske Verlags, 1983, pp. 116-152.

[2] P. H. Fries, "Theme. Methods of development, and texts," in On Subject and Theme: A Discourse Functional Perspective, R. Hasan and P. Fries, Eds. Amsterdam: John Benjaminsl, 1995, pp. 315-359.

[3] M. Q. Huang, "Thematic progression and discourse genre: Taking $A n$ Idyllic Land of Peach-Blossom Spring for example," vol. 11, pp. 16-18, Jan. 2018.

[4] Z. L. Hu, Introduction to Systemic Functional Linguistics, Beijing: Peking University Press, 2005, pp. 164-165.

[5] M. A. K. Halliday and W. X. Peng, An Introduction to Functional Grammar, Beijing: Foreign Language Teaching and Research Press, 2010, pp. 38-39.

[6] F. Danes, Papers on Functional Sentence Perspective, The Hague: Mouton, 1974, pp. 38-38.

[7] S. H. Xu, "Theme and rheme," Foreign Language Teaching and Research, vol. 1, pp. 1-9, Jan. 1982.

[8] Y. Huang, "On theme and rheme in English," Journal of Foreign Languages, vol. 5, pp. 34-38, Oct. 1985.

[9] G. W. Huang, Summary of Discourse Analysis, Changsha: Hunan Education Publishing House, 1988, pp. 81-85.

[10] Z. L. Hu, Cohesion and Coherence in Text, Shanghai: Shanghai Foreign Language Education Press, 1994, pp. 144-155.

[11] Y. S. Zhu, "Thematic progression and text analysis," Foreign Language Teaching and Research, vol. 3, pp. 6-12, Jun. 1995

[12] J. S. Shi, T. Naren, and X. Song, "On thematic progression in texts of stipulated style — The relationship between thematic progression, stylistic type and the theme," Applied Linguistics, vol. 1, pp. 90-99, Mar. 2018.

[13] X. Y. Zuo, "A comparative study of English and Chinese thematic progression patterns-Taking the prose My Private Library and 
English translation version as example," Overseas English, vol. 14, pp. 107, Aug. 2018.

[14] Q. Wang, "A study of studies from cohesion and thematic analysis," Journal of Jiamusi Education Institute, no. 10, pp. 156, Oct. 2013.

[15] D. M. Yu, "Interpretation of the thematic progression patterns of Russell's prose What I Have Lived for," Journal of Mudanjiang Normal University (Philosophy Social Sciences Edition), vol. 3, pp. 123-125, Jun. 2013.

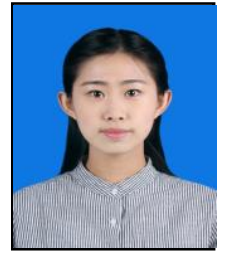

Wang Qingwei was born in Qingdao, Shandong, P.R. China in May 1995. She graduated from Northwestern Polytechnical University (NPU) sited in Xi'an, Shaanxi Province with a bachelor degree as bachelor of arts. She is now studying foreign language linguistics and applied linguistics in the same university for her master degree.

She has attended the 7th Annual International Conference - L3 2018 and presented the article entitled "A Comparative Study of Chinese and German Automobile Advertising Slogans: From the

Perspective of Cooperative Principle" and was awarded Best Student Paper. 